\title{
The Investigation of the Stability of Solid Acid Catalysts in the Process of Larch Arabinogalactan Hydrolysis in Aqueous Medium
}

\author{
Olga V. Yatsenkova, \\ Svetlana A. Novikova, Andrei M. Skripnikov, \\ Ivan P. Ivanov and Boris N. Kuznetsov* \\ Institute of Chemistry and Chemical Technology $S B R A S$ \\ FRC "Krasnoyarsk Science Center SB RAS" \\ 50/24 Akademgorodok, Krasnoyarsk, 660036, Russia
}

Received 21.03.2019, received in revised form 16.04.2019, accepted 11.05.2019

\begin{abstract}
The toxic and corrosive mineral acids are used traditionally in the processes of plant polysaccharides hydrolysis. The use of solid acid catalysts improves the environmental safety of hydrolysis processes and simplifies the separation of the catalyst from the reaction products. The stability of solid acid catalysts based on mesoporous $\mathrm{SBA}-15$ and graphite-like carbon material Sibunit-4, containing $\mathrm{SO}_{3} \mathrm{H}$ groups, in the process of larch arabinogalactan hydrolysis at $150{ }^{\circ} \mathrm{C}$ was studied. The compositions of the resulting hydrolysates were investigated by gas chromatography. It was established that acidmodified Sibunit-4 does not lose the catalytic activity after three cycles of hydrolysis process for a total duration of 12 hours. Modified SBA-15 catalyst was less stable at the studied conditions. The decrease of monosaccharides concentration in the hydrolysates, the changes in the structure of the catalyst and $40 \%$ loss of its weight were found after the third cycle of larch arabinogalactan hydrolysis.
\end{abstract}

Keywords: larch arabinogalactan, hydrolysis, solid acid catalysts, SBA-15, Sibunit-4, Amberlyst-15, stability in aqueous medium, arabinose, galactose.

Citation: Yatsenkova O.V., Novikova S.A., Skripnikov A.M., Ivanov I.P., Kuznetsov B.N. The investigation of the stability of solid acid catalysts in the process of larch arabinogalactan hydrolysis in aqueous medium, J. Sib. Fed. Univ. Chem., 2019, 12(2), 282-295. DOI: 10.17516/1998-2836-0126.

(C) Siberian Federal University. All rights reserved

* Corresponding author E-mail address: yatsenkova@icct.ru 


\title{
Изучение устойчивости твердых кислотных катализаторов \\ в процессе гидролиза арабиногалактана лиственницы
}

в водной среде

\author{
О.В. Яценкова, С.А. Новикова, \\ А.М. Скрипников, И.П. Иванов, Б.Н. Кузнецов \\ Институт химии и химической технологии СО РАН \\ ФИЦ «Красноярский научный иентр СО РАН» \\ Россия, 660036, Красноярск, Академгородок, 50/24
}

Традииионно для гидролиза растительных полисахаридов используются токсичные u коррозионно-активные минеральные кислоты. Применение твердых кислотных катализаторов повымает экологическую безопасность прочессов гидролиза и упрощает отделение катализатора от продуктов реакиии. В настоящей работе исследована устойчивость твердых кислотных катализаторов на основе мезопористого SBA-15 и графитоподобного углеродного материала Сибунит-4, содержащих $\mathrm{SO}_{3} \mathrm{H}$-группьl, в процессе гидролиза арабиногалактана лиственницы при температуре $150{ }^{\circ} \mathrm{C}$. Состав полученных гидролизатов исследован методом газовой хроматографии. Установлено, что кислотномодифицированный Сибунит-4 не снижает каталитическую активность после трех циклов прочесса гидролиза при общем времени работы катализатора 12 ч. Модифицированный катализатор SBA-15 оказался менее устойчивым в изученных условиях, что проявилось в снижении концентрации моносахаров в гидролизатах, а также в изменении его структуры и 40\%-й потере массы после третьего ичика гидролиза.

Ключевые слова: арабиногалактан лиственницы, гидролиз, твердые кислотные катализаторы, SBA-15, Сибунит-4, Amberlyst-15, устойчивость в водной среде, арабиноза, галактоза.

\section{Введение}

Поиск экологически безопасных способов химической переработки растительных полимеров стимулирует применение твердых кислотных катализаторов вместо токсичных и коррозионно-активных минеральных кислот $[1,2]$.

К настоящему времени показана возможность применения в реакциях гидролиза растительных полимеров таких кислотных катализаторов, как цеолиты [3], гетерополикислоты [4], оксиды сульфатированных металлов [5,6], сульфатированный активированный уголь (АС$\mathrm{SO}_{3} \mathrm{H}$ ) [7], ионообменные смолы [8].

Сульфатированные мезопористые силикатные материалы семейства SBA являются весьма привлекательными в качестве кислотных катализаторов благодаря тому, что обладают большой площадью удельной поверхности (до $1000 \mathrm{~m}^{2} / \Gamma$ ), большим объемом пор, прочной высокоупорядоченной 2D-гексагональной пористой структурой $[9,10]$.

Катализаторы, синтезированные на основе углеродных материалов, в зависимости от условий приготовления, различаются удельной площадью поверхности (от 10-300 м²/г для гра-

$$
-283-
$$


фита до 100-2500 м²/г для активированного угля и саж) и распределением пор по размерам (от микропор (<2 нм), мезопор (2-50 нм) до макропор (>50 нм)) [11].

Анализ литературы свидетельствует, что твердые кислотные катализаторы могут стать альтернативой минеральным кислотам в гидролизе полисахаридов при условии их достаточно высокой активности и устойчивости к воздействию водной среды при повышенной температуре [12]. Однако микропористые материалы не полностью подходят для этих целей из-за диффузионных проблем, поэтому цеолиты являются не лучшими катализаторами гидролиза полисахаридов. Для данного процесса предпочтительны мезопористые материалы [13].

В последние годы возник интерес к изучению процессов гидролиза арабиногалактана (АГ) водорастворимого полисахарида, у которого главная цепь макромолекулы состоит из звеньев галактозы, а боковые - из звеньев галактозы и арабинозы. Мономеры D-галактоза и L-арабиноза в настоящее время востребованы как специальные сахара в фармацевтической и косметической промышленности, медицине [14-16]. Арабиноза в виде отдельного моносахарида используется как полупродукт для синтеза витамина $\mathrm{B}_{2}$ и противовирусных препаратов [17].

В работах [18 и 19] показана возможность гидролиза арабиногалактана в присутствии твердых кислотных катализаторов, приготовленных на основе мезопористого углерода, а также коммерческих Smopex-101 и Amberlyst-15. Установлено, что при температуре $185^{\circ} \mathrm{C}$ в гидролизатах, помимо арабинозы и галактозы, присутствуют фурфурол, 5-гидроксиметилфурфурол и гуминовые вещества. При температуре $90{ }^{\circ} \mathrm{C}$ происходит селективный гидролиз арабиногалактана с образованием преимущественно арабинозы.

Ранее [20] нами была изучена кинетика гидролиза арабиногалактана лиственницы в присутствии твердых кислотных катализаторов. Установлено, что константы скорости образования моносахаров (арабинозы и галактозы) при температуре $150{ }^{\circ} \mathrm{C}$ в процессе гидролиза арабиногалактана увеличиваются в ряду катализаторов: Сибунит-4 < SBA-15 < Amberlyst-15.

В литературе имеется мало сведений о стабильности твердых кислотных катализаторов в реакциях гидролиза растительных полисахаридов [2, 21]. Изучение стабильности силикатной матрицы SBA-15 в растворах кислот и щелочей показало, что матрица SBA-15 подвержена значительному растворению в указанных средах, хотя при этом сохраняет свою высокоупорядоченную мезоструктуру [22].

В настоящей работе сопоставлена устойчивость твердых кислотных катализаторов SBA15, Сибунит-4 и Amberlyst-15, содержащих $\mathrm{SO}_{3} \mathrm{H}$-группы, в процессе гидролиза арабиногалактана лиственницы в водной среде при $150{ }^{\circ} \mathrm{C}$.

\section{Экспериментальная часть}

В качестве исходного сырья использовали арабиногалактан древесины лиственницы сибирской - препарат «Фибролар С» производства ООО «Химия древесины» (Иркутск, Россия). Элементный состав арабиногалактана (углерод 44,4 \%, водород 6,7 \%, кислород 48,9 \%) определяли на анализаторе Flash EA-1112 (ThermoQuestItalia).

\section{Синтез и свойства катализаторов}

В качестве твердых кислотных катализаторов гидролиза арабиногалактана использовали содержащие $\mathrm{SO}_{3} \mathrm{H}-г$ руппы SBA-15, Сибунит-4, Amberlyst 15 dry (Acros organics).

$$
-284-
$$






Рис. 1. Снимок SBA-15, полученный методом просвечивающей электронной микроскопии

Fig. 1. Transmission electron microscopy image of SBA-15

Исходный мезоструктурированный SBA-15 представляет собой пространственно упорядоченный силикатный материал [23] с регулируемым размером гексагональных пор в интервале 6-8 нм (рис. 1).

Состав полученного на основе SBA-15 кислотного катализатора, условно имеющего силикатную матрицу, линкер и функциональную группу - $\mathrm{SO}_{3} \mathrm{H}$, можно представить так:

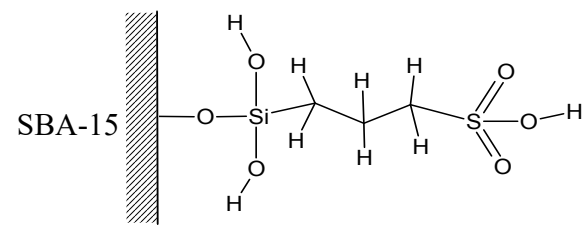

Сибунит-4 - пористый графитоподобный материал, композит из сажи и пиролитической модификации углерода. Гранулы Сибунита имеют сферическую форму и фракционный состав 0,5-3,0 мм. Размолом гранул получают порошок Сибунита с размером частиц 0,2-0,5 мм [24].

Amberlyst-15 представляет собой макропористую ионообменную смолу на основе сополимера стирола и дивинилбензола. Частицы Amberlyst-15 имеют форму сфер с размером 0,450,60 мм [19].

Кислотное модифицирование углеродного мезопористого материала Сибунит-4 проводили, обрабатывая его сначала водным раствором азотной кислоты («хч», ГОСТ 4461-77, Россия), а затем дополнительно концентрированной серной кислотой («хч», ТУ 2612-005-56853252-2003, Россия) по методике [25].

Кислотное модифицирование мезопористого SBA-15 включало прививку 3-меркаптопропилтриметоксисилана $\left(\mathrm{C}_{6} \mathrm{H}_{16} \mathrm{O}_{3} \mathrm{SS}\right.$ SiAldrich, Cat.: 175617) с последующим окислением меркаптогрупп до сульфоновых с использованием 30\%-го раствора пероксида водорода (ГОСТ 177-88, Россия) [2628]. Далее в тексте катализатор SO3H-SBA-15 для упрощения будет обозначаться как SBA-15.

Концентрацию кислотных групп на поверхности катализаторов определяли кислотноосновным титрованием с использованием гидроксида натрия [29].

Текстурные свойства модифицированных образцов были исследованы методом низкотемпературной адсорбции $\mathrm{N}_{2}$ на установке ASAP-2020 (Micrometritics, CША) при T=77 К в интервале относительных давлений $\left(\mathrm{P} / \mathrm{P}^{\circ}\right)$ 0,06-0,99 с шагом 0,015. Удельную площадь поверхности

$$
-285-
$$


рассчитывали по модели ВЕТ в интервале $\mathrm{P} / \mathrm{P}^{0} 0,06-0,25$, внутренний объем пор - по методу «Single Point BET», а распределение пор по размерам получали по уравнению изотермы ВJН. Ширину пор определяли как $4 \mathrm{~V} / \mathrm{S}_{\mathrm{BET}}$.

Регистрацию ИК-спектров проводили на ИК-Фурье спектрометре Tensor 27 (Bruker, Германия) ${ }^{1}$ в интервале частот 400-4000 см․ Таблетки готовили с применением KBr. Навеска образца составляла 2 мг.

\section{Каталитический гидролиз арабиногалактана}

Гидролиз арабиногалактана в присутствии твердых кислотных катализаторов проводили в водной среде при температуре $150{ }^{\circ} \mathrm{C}$ во вращающемся стальном автоклаве с внутренней фторопластовой пробиркой объемом 35 мл, помещенном в металлический воздушный термостат. Скорость вращения автоклава составляла 11 об/мин. Смесь арабиногалактана $(0,075$ г) и твердого катализатора (0,075 г) помещали в пробирку и заливали 15 мл дистиллированной воды. Продолжительность гидролиза 4 ч.

По истечении заданного времени пробирку охлаждали и полученный гидролизат отделяли от твердого катализатора на воронке Бюхнера на бумажном фильтре под вакуумом. Катализатор промывали водой и высушивали в сушильном шкафу при температуре $103{ }^{\circ} \mathrm{C}$, а гидролизат анализировали на содержание сахаров и примесей.

Исследование стабильности твердых кислотных катализаторов в процессе гидролиза арабиногалактана проводили при температуре $150{ }^{\circ} \mathrm{C}$ и продолжительности каждого опыта 4 ч. Общее время работы катализатора составило 12 ч. По истечении заданного времени реакции гидролизат отделяли от твердого катализатора, промывали водой и высушивали, затем использовали повторно.

\section{Анализ состава гидролизатов арабиногалактана}

Индивидуальный состав и содержание моносахаров в гидролизатах АГ исследовали с использованием газового хроматографа «VARIAN-450 GC» с пламенно-ионизационным детектором на капиллярной колонке VF- $624 \mathrm{~ms}$ длиной 30 м, внутренним диаметром 0,32 мм. Пробу гидролизата предварительно подвергали дериватизации по методике [30] с образованием триметилсилильных производных. В качестве силилирующего реагента использовали смесь триметилхлорсилана и гексаметилдисилазана в среде пиридина, а в качестве внутреннего стандарта - сорбит. Идентификацию пиков проводили, используя ранее установленные для данных условий хроматографирования значения времен удерживания $t_{R}$ таутомерных форм моносахаров. Рассчитывали отношение площадей каждого характеристического пика моносахарида к площади пика внутреннего стандарта - сорбита $\left(\mathrm{S}_{\mathrm{i}} / \mathrm{S}_{\mathrm{c \tau}}\right)$. По этим соотношениям с помощью градуировочного графика находили массу каждого моносахарида в пробе гидролизата.

Для определения количественного содержания микропримесей фурфурола, 5-гидроксиметилфурфурола (5-ГМФ) и левулиновой кислоты гидролизаты нейтрализовали карбонатом натрия до рН 5. Пробу гидролизата три раза последовательно экстрагировали этилацетатом («хч», ГОСТ 22300-76, Россия). В делительную воронку вносили пипеткой 2 мл пробы, затем добав-

В Красноярском региональном центре коллективного пользования СО РАН.

$$
-286-
$$


ляли 2 мл этилацетата. Воронку интенсивно встряхивали и давали отстояться до разделения фаз, после чего отделяли фазу этилацетата. К 1 мл этилацетатного экстракта добавляли 0,4 мл антрацена (внутренний стандарт) и проводили хроматографирование. Для расчета содержания левулиновой кислоты, фурфурола и 5-ГМФ использовали градуировочные графики.

В качестве стандартов для анализа гидролизатов использовали арабинозу (Panreac, Германия), галактозу (Рanreac, Германия), сорбит (Panreac, Германия), антрацен (Sigma-Aldrich, США), фурфурол (Sigma-Aldrich, США), 5-гидроксиметил-2-фуральдегид (Sigma-Aldrich, США), левулиновую кислоту (Sigma-Aldrich, США).

\section{Результаты и их обсуждение}

В табл. 1 представлены текстурные характеристики кислотно-модифицированных катализаторов, определенные методом адсорбции азота при 77 К. Показано, что в результате химической модификации катализаторов наблюдается закономерное уменьшение их удельной поверхности.

Установлено, что после обработки азотной кислотой удельная площадь поверхности Сибунита-4 уменьшилась на $5 \%$, а после обработки серной кислотой - на $26 \%$ по сравнению с исходным Сибунитом, а диаметр пор увеличился на 20 \% с 5,1 до 6,1 нм (табл. 1).

Кислотное модифицирование мезопористого SBA-15 приводит к уменьшению удельной поверхности матрицы катализатора на 17 \% и диаметра пор на 24 \%, что может свидетельствовать о высокой доступности поверхности для проникновения модификатора в глубину пор и успешной прививке функциональных групп к матрице SBA-15.

Каталитические свойства твердых кислотных катализаторов Сибунита-4, SBA-15 и Amberlyst-15 в гидролизе арабиногалактана лиственницы исследованы при температуре $150{ }^{\circ} \mathrm{C}$ и начальной концентрации АГ 5 г/л.

Установлено, что при продолжительности процесса гидролиза 4 ч в присутствии катализаторов SBA-15 и Amberlyst-15 происходит практически полный гидролиз арабиногалактана, и содержание галактозы и арабинозы в гидролизатах составляет 4,3-4,2 и 0,6-0,55 г/л соответственно (рис. 2). Полученные гидролизаты содержат также «следовые» количества ( 0,001 г/л) продуктов вторичных превращений арабинозы и галактозы в фурановые соедине-

Таблица 1. Текстурные характеристики катализаторов и содержание кислотных групп

Table 1. Textural characteristics of the catalysts and the content of acid groups

\begin{tabular}{|l|c|c|c|c|c|}
\hline \multicolumn{1}{|c|}{ Катализатор } & $\mathrm{S}_{\mathrm{BET}}, \mathrm{M}^{2} / \Gamma$ & $\begin{array}{c}\mathrm{S}_{\text {meso }} \text { мезопор, } \\
\mathbf{m}^{2} / \Gamma\end{array}$ & $\begin{array}{c}\mathrm{V}_{\text {пор }}(\mathrm{SP}), \\
\text { см}^{3} / \Gamma\end{array}$ & $\begin{array}{c}\mathrm{D}_{\text {пор }}(\mathrm{BJH}), \\
\text { нм }\end{array}$ & $\begin{array}{c}\mathrm{C}_{\text {кисл. }} \\
\text { ммоль/ }\end{array}$ \\
\hline Исходный Сибунит-4 & 349 & 333 & 0,45 & 5,1 & 0,05 \\
\hline Сибунит-4, обработанный $\mathrm{HNO}_{3}$ & 333 & 291 & 0,42 & 5,0 & 0,17 \\
\hline $\begin{array}{l}\text { Сибунит-4, обработанный } \\
\mathrm{HNO}_{3}+\mathrm{H}_{2} \mathrm{SO}_{4}\end{array}$ & 258 & 191 & 0,39 & 6,1 & 0,13 \\
\hline Исходный SBA-15 & 595 & 420 & 0,77 & 6,2 & - \\
\hline $\mathrm{SO}_{3} \mathrm{H}-\mathrm{SBA-15}$ & 495 & 363 & 0,59 & 4,7 & 0,41 \\
\hline Amberlyst-15 [31] & 45 & - & 0,31 & 40,0 & 4,70 \\
\hline
\end{tabular}




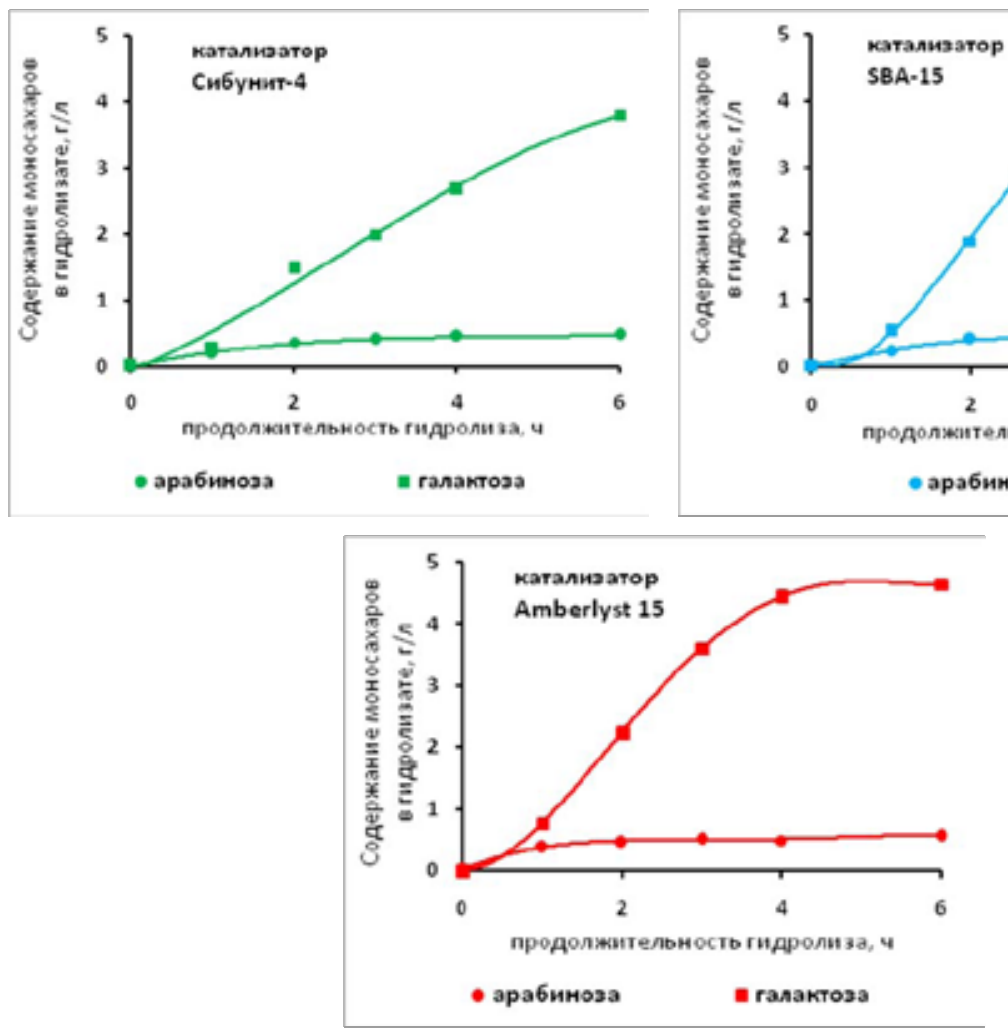

Рис. 2. Влияние природы твердых кислотных катализаторов и продолжительности гидролиза арабиногалактана на содержание моносахаров в гидролизатах при температуре $150{ }^{\circ} \mathrm{C}$

Fig. 2. Influence of nature of solid acid catalysts and reaction time of arabinogalactan hydrolysis on the content of monosaccharides in hydrolysates (temperature $150^{\circ} \mathrm{C}$ )

ния (фурфурол и 5-ГМФ). Пониженная каталитическая активность Сибунита-4 в гидролизе арабиногалактана при $150{ }^{\circ} \mathrm{C}$ объясняется меньшей площадью удельной поверхности и невысоким содержанием кислотных групп в его составе по сравнению с модифицированным SBA-15 (табл. 1).

Данные о снижении активности катализаторов в процессе гидролиза АГ при температуре $150{ }^{\circ} \mathrm{C}$ приведены на рис. 3 .

Результаты проведенных экспериментов показывают, что в гидролизатах арабиногалактана, полученных в присутствии катализаторов SBA-15 и Amberlyst-15, содержание арабинозы остается постоянным, а содержание галактозы к третьему опыту снижается с 4,3 до 3,4 г/л и с 4,2 до 1,7 г/л соответственно (рис. 3). Каталитическая активность Сибунита-4 не снижается при его трехкратном использовании в течение 12 ч (рис. 3). Концентрация моносахаров остается постоянной в каждом из трех опытов и составляет 2,6 г/л галактозы и 0,4 г/л арабинозы. Полученные результаты хорошо согласуются с данными работ $[7,11,21]$ о сохранении исходной активности углеродных катализаторов при их многократном использовании в реакции гидролиза целлюлозы при температурах 100-150 $\mathrm{C}$ в течение 6-24 ч.

В течение трех каталитических циклов происходит снижение каталитической активности (по содержанию галактозы в гидролизате) Amberlyst-15 в 1,3 раза, а SBA-15 в 2,4 раза. Мо- 


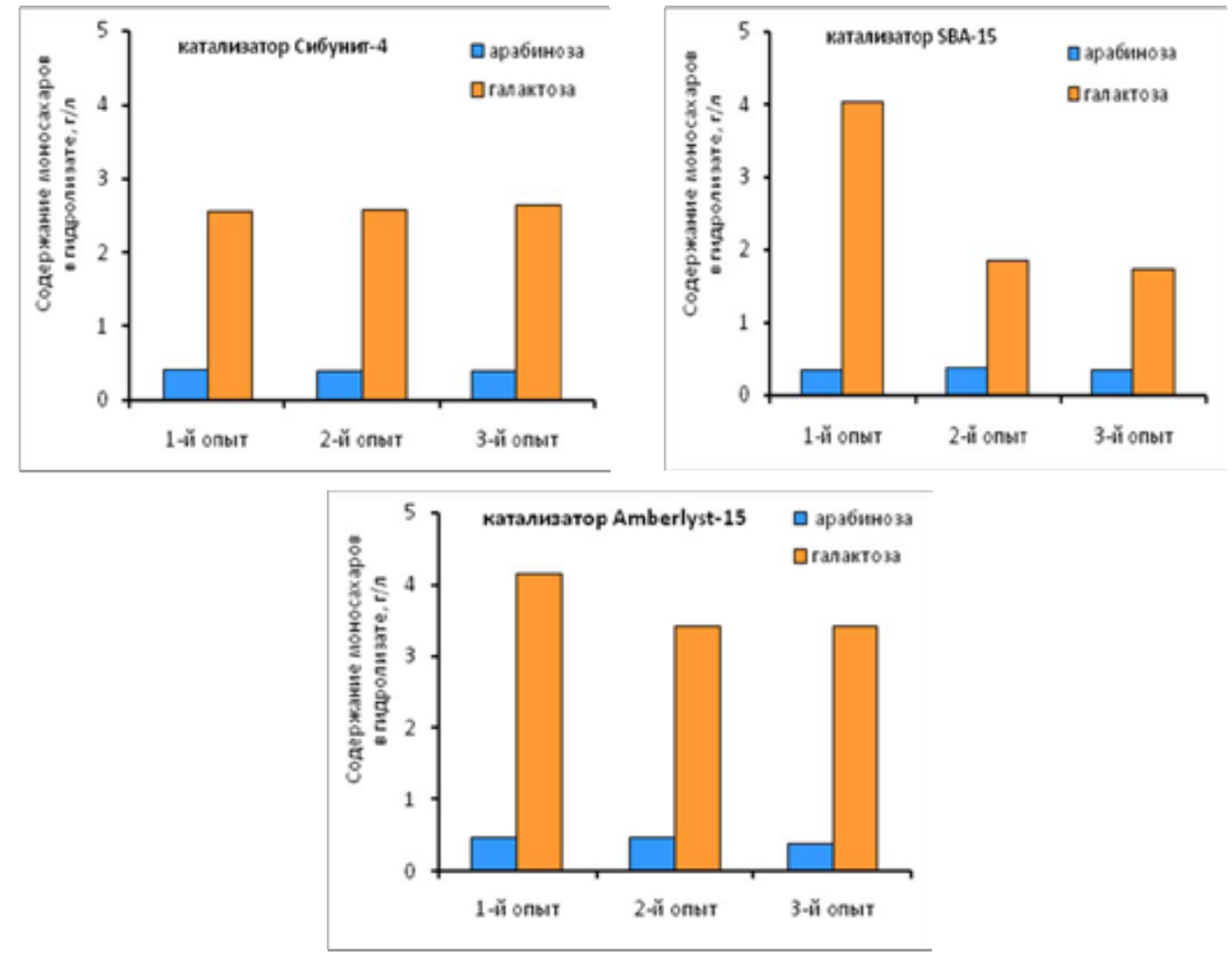

Рис. 3. Снижение активности катализаторов в процессе гидролиза арабиногалактана лиственницы при температуре $150{ }^{\circ} \mathrm{C}$ и продолжительности каждого опыта 4 ч

Fig. 3. Decrease of the catalysts activity in the process of larch arabinogalactan hydrolysis (temperature $150{ }^{\circ} \mathrm{C}$ and reaction time of each experiment 4 hours)

дифицированный Сибунит-4 в процессе гидролиза арабиногалактана при температуре $150{ }^{\circ} \mathrm{C}$ является менее активным катализатором по сравнению с коммерческим Amberlyst-15 и модифицированным SBA-15, однако он более стабилен в изученных условиях процесса.

На рис. 4 представлены изотермы низкотемпературной адсорбции-десорбции азота (а) и графики распределения пор по размерам (б) для катализатора SBA-15 до гидролиза и после трех циклов его использования в процессе гидролиза арабиногалактана при $150{ }^{\circ} \mathrm{C}$.

Согласно классификации ИЮПАК указанные образцы характеризуются изотермами IV типа. Анализ кривых распределения пор по размерам показывает, что максимум распределения пор для образца SBA-15 после 2-го цикла гидролиза смещается с 7,33 до 8,54 нм, интенсивность максимума распределения падает и распределение становится более широким. После 3-го цикла гидролиза смещение максимума распределения еще больше сдвигается в сторону увеличения диаметра до 10,03 нм.

Таким образом, при продолжительности процесса каталитического гидролиза арабиногалактана 12 ч в структуре катализатора SBA-15 наблюдаются следующие изменения: удельная поверхность возрастает от 495 до $604 \mathrm{~m}^{2} / \Gamma$, объем и средний диаметр пор увеличиваются от 0,59 до $1,02 \mathrm{~cm}^{3} / \Gamma$ и от 4,7 до 6,8 нм соответственно (табл. 2). Потеря массы катализатора сопровождается частичным удалением привитых органических групп, содержа- 



Рис. 4. Изотермы низкотемпературной адсорбции-десорбции азота (а) и графики распределения пор по размерам (б) для катализатора SBA-15 до и после трех циклов гидролиза арабиногалактана (температура $150{ }^{\circ} \mathrm{C}$, продолжительность каждого опыта 4 ч). Изотермы смещены друг относительно друга на $200 \mathrm{~cm}^{3} / \Gamma$, кривые распределения - на $0,02 \mathrm{~cm}^{3} / \Gamma \cdot \AA$

Fig. 4. The nitrogen low-temperature adsorption isoterms (a) and the pore size distribution plots (б) for the acid-modified catalyst SBA-15 before and after three cycles of larch arabinogalactan hydrolysis (temperature of process $150{ }^{\circ} \mathrm{C}$, reaction time of each experiment 4 hours). The isoterms are shifted along Y-axis from each other for $200 \mathrm{~cm}^{3} / \mathrm{g}$, and pore size distribution plots - for $0,02 \mathrm{~cm}^{3} / \mathrm{g} \cdot \AA$

щих $-\mathrm{SO}_{3} \mathrm{H}$ [22]. В результате этого снижается содержание сульфогрупп в катализаторе с 0,41 до 0,09 ммоль/г.

На рис. 5 приведены изотермы низкотемпературной адсорбции-десорбции азота и графики распределения пор по размерам для Сибунита-4 до гидролиза и после трех циклов его использования в процессе гидролиза арабиногалактана. Изотермы для всех образцов катализатора мало различаются. Лишь наблюдается незначительное смещение максимума на графиках распределения пор по размерам для образцов катализатора после их использования в процессе гидролиза арабиногалактана при $150{ }^{\circ} \mathrm{C}$ в течение 8-12 ч. Для них наблюдается небольшое увеличение среднего диаметра пор, сопровождаемое уменьшением площади удельной поверхности с 258 до $162 \mathrm{~m}^{2} / \Gamma$, однако содержание кислотных групп практически не изменяется и не происходит потери массы катализатора.

В ИК-спектрах (рис. 6) образцов SBA-15 в области 400-1200 см-1 наблюдаются три полосы, отвечающие колебаниям $\mathrm{Si}-\mathrm{O}-\mathrm{Si}$-связей в тетраэдре $\mathrm{SiO}_{4}$. Широкая п.п. при 3440-3480 см-1 и менее, интенсивные полосы при 1600-1640 и 2344-2368 см-1 соответствуют колебаниям вицинальных силанольных групп, а узкая п.п. при 3745-3750 см-1 - изолированным силанольным группам [32]. После гидролиза арабиногалактана в течение 12 ч на ИК-спектре SBA-15 наблюдается снижение интенсивности полос в области 2930-2960 см-1, что указывает на удаление из катализатора органических функциональных групп, содержащих $-\mathrm{SO}_{3} \mathrm{H}$. 



Рис. 5. Изотермы низкотемпературной адсорбции-десорбции азота (а) и графики распределения пор по размерам (б) для модифицированного Сибунита-4 до и после трех циклов гидролиза арабиногалактана (температура $150{ }^{\circ} \mathrm{C}$, продолжительность каждого опыта 4 ч). Изотермы смещены друг относительно друга на $100 \mathrm{~cm}^{3} / \Gamma$, кривые распределения - на $0,0003 \mathrm{~cm}^{3} / \Gamma \cdot \AA$

Fig. 5. The nitrogen low-temperature adsorption isoterms (a) and the pore size distribution plots (б) for the acidmodified catalyst Sibunit-4 before and after three cycles of larch arabinogalactan hydrolysis (temperature of process $150{ }^{\circ} \mathrm{C}$, reaction time of each experiment 4 hours). The isoterms are shifted along Y-axis from each other for $100 \mathrm{~cm}^{3} / \mathrm{g}$, the distribution curves by $0.0003 \mathrm{~cm}^{3} / \mathrm{g} \cdot \AA$

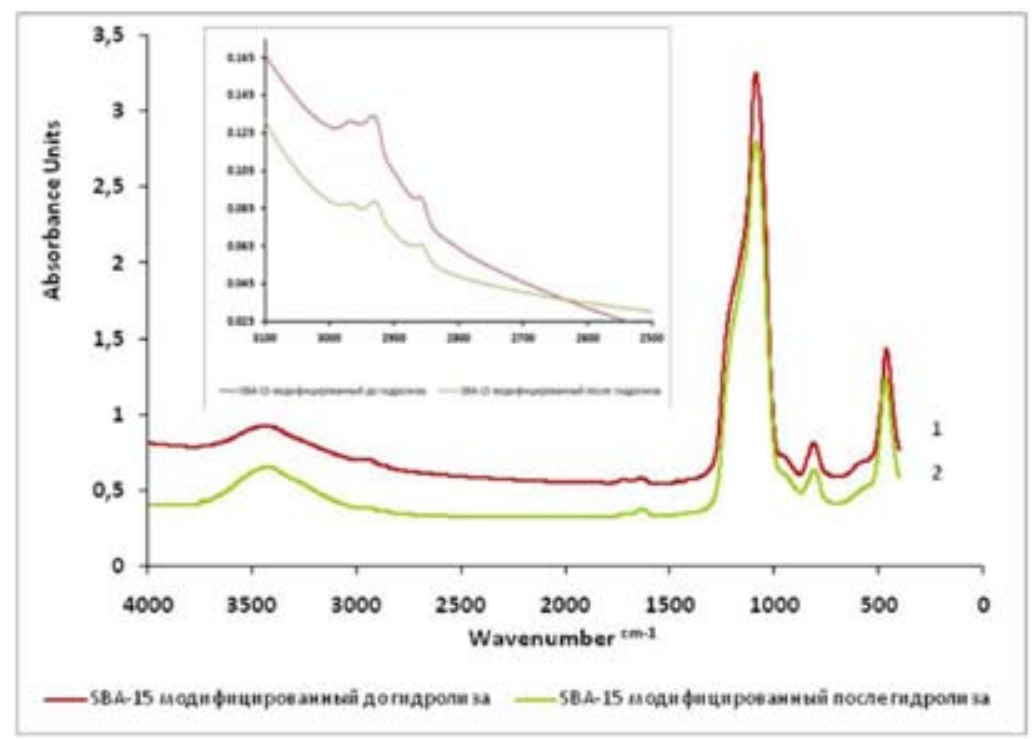

Рис. 6. ИК-спектры SBA-15 до гидролиза (1) и после гидролиза 12 ч (2)

Fig. 6. IR spectra of SBA-15 before (1) and after (2) larch arabinogalactan hydrolysis for $12 \mathrm{~h}$ 
Таблица 2. Изменения в текстурных характеристиках катализаторов SBA-15 и Сибунит-4, содержании кислотных групп в процессе гидролиза арабиногалактана при $150{ }^{\circ} \mathrm{C}$

Table 2. Changes in the textural characteristics of the catalysts SBA-15 and Sibunit-4 and the content of acid groups in the process of larch arabinogalactan hydrolysis at $150{ }^{\circ} \mathrm{C}$

\begin{tabular}{|c|c|c|c|c|c|c|c|}
\hline $\begin{array}{c}\text { Образец кислотно- } \\
\text { модифицированного } \\
\text { катализатора }\end{array}$ & 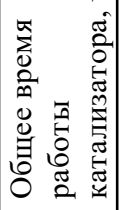 & $\begin{array}{c}\text { Потеря массы } \\
\text { катализатора, \%ํㅜㄹ }\end{array}$ & $\begin{array}{l}\mathrm{S}_{\mathrm{BET}}, \\
\mathrm{M}^{2} / \Gamma\end{array}$ & $\begin{array}{c}\mathrm{S}_{\text {meso }}, \\
\mathbf{M}^{2} / \Gamma\end{array}$ & $\begin{array}{c}\mathrm{V}_{\text {пор }}(\mathrm{SP}), \\
\mathrm{cm}^{3} / \Gamma\end{array}$ & $\begin{array}{l}\text { Средний } \mathrm{D}_{\text {пор }} \\
\left(4 \mathrm{~V} / \mathrm{S}_{\mathrm{BET}}\right), \mathrm{HM}\end{array}$ & $\begin{array}{c}\mathrm{C}_{\text {кисл.гр. }}, \\
\text { ммоль/г }\end{array}$ \\
\hline SBA-15 до гидролиза & - & - & 495 & 363 & 0,59 & 4,7 & 0,41 \\
\hline $\begin{array}{l}\text { SBA-15 после гидролиза } \\
\text { арабино-галактана: } \\
\text { 1-й опыт } \\
\text { 2-й опыт } \\
\text { 3-й опыт }\end{array}$ & $\begin{array}{c}4 \\
8 \\
12\end{array}$ & $\begin{array}{l}25 \\
36 \\
40\end{array}$ & $\begin{array}{l}489 \\
597 \\
604\end{array}$ & $\begin{array}{l}325 \\
518 \\
556\end{array}$ & $\begin{array}{l}0,71 \\
0,89 \\
1,02\end{array}$ & $\begin{array}{l}5,9 \\
6,0 \\
6,8\end{array}$ & $\begin{array}{l}0,11 \\
0,09 \\
0,09\end{array}$ \\
\hline Сибунит-4 до гидролиза & - & - & 258 & 191 & 0,39 & 6,1 & 0,13 \\
\hline $\begin{array}{l}\text { Сибунит-4 после } \\
\text { гидролиза арабино- } \\
\text { галактана: } \\
\text { 1-й опыт } \\
\text { 2-й опыт } \\
\text { 3-й опыт }\end{array}$ & $\begin{array}{c}4 \\
8 \\
12\end{array}$ & $\begin{array}{l}1 \\
1 \\
1\end{array}$ & $\begin{array}{l}182 \\
176 \\
162\end{array}$ & $\begin{array}{l}175 \\
164 \\
150\end{array}$ & $\begin{array}{l}0,34 \\
0,36 \\
0,33\end{array}$ & $\begin{array}{l}7,3 \\
8,1 \\
8,2\end{array}$ & $\begin{array}{l}0,13 \\
0,13 \\
0,13\end{array}$ \\
\hline
\end{tabular}

${ }^{1}$ От массы исходной навески.

\section{Заключение}

Исследована устойчивость твердых кислотных катализаторов на основе мезопористого SBA-15 и графитоподобного углеродного материала Сибунит-4, содержащих $\mathrm{SO}_{3} \mathrm{H}-$ группы, в процессе гидролиза арабиногалактана лиственницы в водной среде при температуре $150{ }^{\circ} \mathrm{C}$.

Установлено, что модифицированный Сибунит-4 устойчив в гидротермальных условиях и способен длительное время (12 ч) работать, не снижая каталитической активности. Концентрации арабинозы и галактозы в гидролизатах, полученных в присутствии Сибунита-4, не снижаются за три цикла работы катализатора при температуре $150{ }^{\circ} \mathrm{C}$. По этому показателю Сибунит-4 превосходит катализаторы SBA-15 и коммерческий Amberlyst-15, содержащие $\mathrm{SO}_{3} \mathrm{H}-$ функциональные группы. После использования в процессе гидролиза при $150{ }^{\circ} \mathrm{C}$ в течение 12 ч площадь удельной поверности Сибунита-4 слегка уменьшается при некотором увеличении диаметра пор. При этом общий объем пор и содержание кислотных групп на поверхности, масса катализатора остаются постоянными.

Модифицированный катализатор SBA-15 менее устойчив в изученных условиях процесса гидролиза арабиногалактана, что проявилось в снижении его активности после второго и третьего каталитического цикла и изменении его структурных характеристик: удельная поверхность, объем и диаметр пор увеличились, а содержание кислотных групп снизилось в 4,5 раза. Изменение структуры катализатора SBA-15 сопровождалось 40\%-ной потерей массы после третьего цикла процесса гидролиза. 


\section{Список литературы}

1. Dhepe P.L., Sahu R. A solid-acid-based process for the conversion of hemicelluloses. Green Chemistry 2010. Vol. 12, P. 2153-2156.

2. Barbaro P., Liguori F. Ion exchange resins: catalyst recovery and recycle. Chem. Rev. 2009. Vol. 109 (2), P. 515-529.

3. Tamura M., Chaikittisilp W., Yokoi T., Okubo T. Incorporation process of Ti species into the framework of MFI type zeolite. Microporous and Mesoporous Materials 2008. 112. P. 202-210.

4. Palkovits R., Tajvidi K., Ruppert A.M., Procelewska J. Heteropoly acids as efficient acid catalysts in the one-step conversion of cellulose to sugar alcohols. Chem. Commun. 2011. 47, P. 576-578.

5. Kaur K., Wanchoo R.K., Toor A.P. Sulfated Iron Oxide: A Proficient Catalyst for Esterification of Butanoic Acid with Glycerol. Ind. Eng. Chem. Res. 2015. 54 (13), P. 3285-3292.

6. Varala R., Kulakarni S.R., Khan M., Alwarthan A., Adil S.F. Sulfated tin oxide (STO) Structural properties and application in catalysis: A review. Arabian Journal of Chemistry. 2016. Vol. 9. Issue 4, P. 550-573.

7. Onda A., Ochi T., Yanagisawa K. Selective hydrolysis of cellulose into glucose over solid acid catalysts. Green Chem. 2008. 10(10), P. 1033-1037.

8. Siril P.F., Cross H.E., Brown D.R. New polystyrene sulfonic acid resin catalysts with enhanced acidic and catalytic properties. Journal of Molecular Catalysis A Chemical. 2008. 279(1) P. 63-68.

9. Degirmenci V., Uner D., Cinlar B. et al. Sulfated Zirconia Modified SBA-15 Catalysts for cellobiose hydrolysis. Catalysis Letters. 2011. Vol. 141, P. 33-42.

10. Takagaki A., Nishimura M., Nishimura S. et al. Hydrolysis of sugars using magnetic silica nanoparticles with sulfonic acid groups. Chem. Lett. 2011. Vol. 40, P. 1195-1197.

11. Suganuma S., Nakajima K., Kitano M. at al. Hydrolysis of cellulose by amorphous carbon bearing $\mathrm{SO}_{3} \mathrm{H}, \mathrm{COOH}$ and $\mathrm{OH}$ groups. J. Am. Chem. Soc. 2008. 130, P. 12787-12793.

12. Vilcocq L., Castilho P.C., Carvalheiro F., Duarte L.C. Hydrolysis of oligosaccharides over solid acid aatalysts: A review. Chem Sus Chem. 2014. 7, P. 1010-1019.

13. He Y., Hoff T.C., Emdadi L., Wu Y., Bouraima J., Liu D. Catalytic consequences of micropore topology, mesoporosity and acidity on the hydrolysis of sucrose over zeolite catalysts. Catal. Sci. Technol. 2014. 4, P. 3064-3073.

14. Stephen A.M., Phillips G.O., Williams P.A. Food polysaccharides and their applications. CRC. Taylor and Francis Group. Boca Raton, London, NW. 2006. 734 p.

15. Lanzer P., Lipton M. Diagnostics of vascular diseases. Principles and Technology. Springer. 1997. $361 \mathrm{p}$.

16. Schlief R., Alhassan A., Wiggins J., Schumann W., Niendorf H.-P. Safety of the galactosebased ultrasound contrast agent Levovist. Academic radiology. 2002. Vol. 9. (1), P. 240-242.

17. Helanto M., Kiviharju K., Granström T., Leisola M., Nyyssölä A. Biotechnological production of L-ribose from L-arabinose. Appl Microbiol Biotechnol. 2009. Vol. 83, P. 77-83.

18. Murzin D.Yu., Murzina E.V., Tokarev A., Shcherban N.D., Wärnå J., Salmi T. Arabinogalactan hydrolysis and hydrolytic hydrogenation using functionalized carbon materials. Catalysis Today 2015. Vol. 257, P. 169-176. 
19. Kusema B.T., Hilmann G., Mäki-Arvela P., Willför S., Holmbom B., Salmi T., Murzin D.Yu. Selective hydrolysis of arabinogalactan into arabinose and galactose over heterogeneous catalysts. CatalLett 2011. Vol. 141, P. 408-412.

20. Яценкова О.В., Скрипников А.М., Козлова С.А., Кузнецов Б.Н. Кинетическое исследование и оптимизация процессов гидролиза арабиногалактана лиственницы в присутствии растворенных и твердых кислотных катализаторов. Журнал Сибирского федерального университета. Химия. 2018. 2 (11), C. 167-183. [Yatsenkova O.V., Skripnikov A.M., Kozlova S.A., Kuznetsov B.N. The Kinetic Investigation and Optimization of the Processes of Larch Arabinogalactane Hydrolysis in the Presence of Dissolved and Solid Acid Catalysts. Journal of Siberian Federal University. Chemistry. 2018. 2 (11). C. 167-183. (In Russ.)]

21. Yatsenkova O.V., Chudina A.I., Kozlova S.A., Skripnikov A.M., Taran O.P., Chesnokov N.V., Kuznetsov B.N. Influence of the nature of acid solid catalysts on their activity in the hydrolysis of sucrose and cellulose. Journal of Siberian Federal University. Chemistry. 2014. 2 (7), P. 226-235.

22. Kozlova S.A., Kirik S.D. Post-synthetic activation of silanol covering in the mesostructured silicate materials MCM-41 and SBA-15. Microporous and Mesoporous Materials. 2010. Vol. 133, P. 124-133.

23. Zhao D.Y., Feng J. L., Huo Q.S. et. al. Triblock copolymer syntheses of mesoporous silica with periodic 50 to 300 angstrom pores. Science. 1998. Vol. 279, P. 548-552.

24. Романенко А.В., Симонов П.А. Углеводородные материалы и их физико-химические свойства. Промышленный катализ в лекциях. 2007. № 7, С. 31-35. [Romanenko A.V., Simonov P.A. Hydrocarbon materials and their physico-chemical properties. Industrial catalysis in lectures. 2007. No. 7, P. 31-35.]

25. Pang J., Wang A., Zheng M., Zhang T. Hydrolysis of cellulose into glucose over carbons sulfonated at elevated temperatures. Chem. Commun. 2010. Vol. 46, P. 6935-6937.

26. Козлова С.А., Парфенов В.А., Кирик С.Д. Сорбционные свойства мезопористых силикатов, функционализированных тиольными группами. Журнал Сибирского федерального университета. Техника и технологии. 2015. Т. 8(4), C. 494-506. [Kozlova S.A., Parfenov V.A., Kirik S.D. Adsorption Properties of Thiol-Functionalized Mesoporous Silica. Journal of Siberian Federal University. Engineering \& Technologies. 2015. Vol. 8(4), P. 494-506. (In Russ.)]

27. Song S.-W., Hidajat K., Kawi S. Functionalized SBA-15 materials as carriers for controlled drug delivery: influence of surface properties on matrix-drug interactions. Langmuir. 2005.21 (21), P. 9568-9575.

28. Melero J.A., Grieken R., Morales G. Advances in the synthesis and catalytic applications of organosulfonic-functionalized mesostructured materials. Chem. Rev. 2006. V.106, P. 3790-3812.

29. Полянская Е.M., Таран О.П. Исследование функциональных групп на поверхности окисленного углеродного материала Сибунит методами кислотно-основного титрования и РФЭС. Вестник Томского государственного университета. Химия. 2017. № 10, С. 6-26. [Polyanskaya E.M, Taran O.P. The study of functional groups on the surface of the oxidized carbon material Sibunit using acid-base titration and XPS. Bulletin of Tomsk State University. Chemistry. 2017. 10. P. 6-26. (In Russ.)]

30. Ruiz-Matute A.I., Hernandez-Hernandez O., Rodriguez-Sanchez S., Sanz M.L., MartinezCastro I. Derivatization of carbohydrates for GC and GC-MS analyses. J. Chromatogr. B. 2011. Vol. 879, P. 1226-1240. 
31. Liu F., Meng X., Zhang Y., Ren L., Nawaz F., Xiao F.-Sh. Efficient and stable solid acid catalysts synthesized from sulfonation of swelling mesoporous polydivinylbenzenes. Journal of Catalysis. 2010. 271, Р. 52-58.

32. Химия привитых поверхностных соединений / ред. Г.В. Лисичкин. М.: Физматлит, 2003. 592 c. [Chemistry of grafted surface compounds. Ed. G.V. Lisichkin. M.: Fizmatlit, 2003. 592 p. (In Russ.)] 